\title{
Does Gender Influence Quality of Life in Children with Atopic Dermatitis?
}

\author{
Slavenka Janković ${ }^{1}$, Milena Ražnatović Đurović , Anđa Ćirković ${ }^{3}$, \\ Janko Janković ${ }^{4}$
}

(1) Institute of Epidemiology, Faculty of Medicine, University of Belgrade, Belgrade, Serbia.

(2) Clinic of Dermatology and Venereology, Clinical Center of Montenegro, Faculty of Medicine, University of Montenegro, Podgorica, Montenegro.

(3) Institute of Medical Statistics and Informatics, Faculty of Medicine, University of Belgrade, Belgrade, Serbia.

(4) Institute of Social Medicine, Faculty of Medicine, University of Belgrade, Belgrade, Serbia.

\section{Correspondence:}

JANKO JANKOVIĆ

E: drjankojankovic@yahoo.com

T: 381112643830

M: +381637767839

\section{ARTICLE INFO}

Received: $18^{\text {th }}$ December 2018 Revision received: $11^{\text {th }}$ January 2019 Accepted: 19 $19^{\text {th }}$ February 2019

\section{INTRODUCTION}

Atopic dermatitis (AD) is the commonest chronic inflammatory skin disease in children with a significant burden on healthcare resources. ${ }^{1-3}$

Although AD may occur at any age, it most often begins in infancy and childhood. The prevalence estimates of $\mathrm{AD}$ vary worldwide, with highest prevalence in developed, high-income countries, where $\mathrm{AD}$ affects over $20 \%$ of children.4,5 Over the last few decades the number of $\mathrm{AD}$ patients has doubled in most parts of the world, especially in low-income countries. ${ }^{3} \mathrm{AD}$ has a great im- pact on quality of life (QoL) of the affected children. $^{6-9}$ In order to effectively use QoL results, it is important to know about existing gender differences in QoL assessment. However, previously reported results concerning gender differences in QoL of young (o-4 age) and older children (5-16 ages) with $\mathrm{AD}$ were contradictory. ${ }^{10-16}$

The purpose of this study was to analyze gender differences in health-related QoL in older children (5-16 years of age) suffering from $\mathrm{AD}$. 


\section{METHODS}

\section{Study design and participants}

A cross-sectional study was carried out at the Clinic of Dermatology and Venereology, Clinical Center of Montenegro (CCM) in Podgorica between August 2017 and July 2018. The study included 200 children (78 boys and 122 girls) aged 5 to 16 years with confirmed AD diagnosis made using Hanifin and Rajka criteria. ${ }^{17}$ The study was approved by the Ethics Committee of the CCM, Podgorica. Written informed consent was obtained from parents of all 200 children with AD.

\section{Data collection}

Socio-demographic data on children with AD (child's gender, age, concomitant atopic disease and family history of atopic disease) were collected by a short questionnaire.

Disease severity was assessed using the Three Item Severity (TIS) score, which corresponds well with the more detailed objective SCORAD (SCORing Atopic Dermatitis) index. ${ }^{18,19}$ It is a simple scoring system which use three of the intensity items of the SCORAD index: erythema (o-3), edema (o-3), and excoriations $(0-3)$ in one or several different representative areas with the maximum score of 9. Based on the TIS, the severity of $\mathrm{AD}$ was classified into mild $(<3)$, moderate $(3-5)$ and severe $(\geq 6)$.

The health related QoL of children was measured using the Children's Dermatology Life Quality Index (CDLQI). The CDLQI is a specific QoL instrument for measurement of impact of skin diseases on QoL of children aged between 5 and 16 years. $^{20}$ It is 10 item structured questionnaire that assess symptoms and feelings (2 items), leisure (3 items), school or holidays (1 item), personal relationships (2 items), sleeping ( 1 item) and treatment ( 1 item). All questions are related to the week preceding its application. The item related to assessment of impact of $\mathrm{AD}$ on school activities has an alternative option to assess the effect of $\mathrm{AD}$ on holiday activities, in case the child is evaluated during school holidays. If both options are rated by a child, higher of the two scores is included in the total CDLQI score. Answers are scored on a 4-point scale from o (not at all) to 3 (very much). The CDLQI total score is calculated by summing the score of each question $(\mathrm{O}-3)$ resulting in a minimum of $\mathrm{o}$ and a maximum of 30 . The higher the score, the more QoL is impaired. Serbian version of CDLQI has been validated previously. ${ }^{21}$ The severity banding of total CDLQI score is suggested as follows: 0 to 1 - no effect; 2 to 6 - small effect; 7 to 12 - moderate effect; 13 to 18 - very large effect and 19 to 30 - extremely large effect of $\mathrm{AD}$ on child's life. ${ }^{22}$

\section{Statistical analysis}

Descriptive statistics were used to describe the cohort of children. Continuous variables were presented as mean $\pm \mathrm{SD}$, and categorical values as frequencies and percentages. To assess differences between variables in boys and girls, Hi square test and Student's t-test were used where appropriate. Correlation between CDLQI scores and $\mathrm{AD}$ severity (TIS score) was assessed using Pearson's correlation coefficients. Multivariate logistic regression analyses were performed with gender as dependent variable and age, concomitant atopic disease, diseases severity (TIS score), CDLQI overall score and family history of disease as independent variables. Cronbach's alpha was applied to assess the reliability of CDLQI. A two-tailed probability value of 0.05 or less was considered significant. All statistical analyses were performed with the Statistical Package for the Social Sciences (SPSS), version 20.0 for Windows (SPSS Inc., Chicago, IL, USA).

\section{RESULTS}

Socio-demographic and clinical characteristics of the study sample $(n=200)$ according to gender are presented in Table 1.There were no significant differences between boys (78) and girls (122) in mean age, concomitant atopic disease, family history of atopic diseases, and diseases severity.

The overall CDLQI score and scores for all 10 items of CDLQI according to gender are shown in Table 2. The mean CDLQI score of the total sample was $17.11 \pm 5.89$. The difference in overall CDLQI between boys and girls was not statistically significant $(P=0.217)$. Overall, the domains that were most affected by $\mathrm{AD}$ were school/holidays (mean score 2.27 \pm 0.65 ), symptoms (mean score $2.22 \pm 0.70$ ), followed by friendships $(1.86 \pm 0.85)$ and leisure/hob- 
Table 1: Characteristics of the study sample according to gender

\begin{tabular}{|c|c|c|c|c|}
\hline Characteristic & All & Boys & Girls & $P$ \\
\hline Total sample & $200(100)$ & $78(39.0)$ & $122(61.0)$ & \\
\hline \multicolumn{5}{|l|}{ Age } \\
\hline Range & $5-16$ & $5-16$ & $6-16$ & \\
\hline Mean \pm SD & $11.68 \pm 2.73$ & $11.742 \pm 2.54$ & $11.64 \pm 2.86$ & $0.793^{*}$ \\
\hline \multicolumn{5}{|l|}{ Atopy } \\
\hline AD alone & $78(39.0)$ & $34(43.6)$ & $44(36.1)$ & $0.287^{\star \star}$ \\
\hline$A D$ and atopic disease & $122(61.0)$ & $44(56.4)$ & $78(63.9)$ & \\
\hline \multicolumn{5}{|c|}{ Family history of atopic disease } \\
\hline Yes & $155(77.5)$ & $56(71.8)$ & $99(81.1)$ & $0.122^{\star \star}$ \\
\hline NO & $45(22.5)$ & $22(28.2)$ & $23(18.9)$ & \\
\hline \multicolumn{5}{|l|}{ Disease severity, $\mathrm{n}(\%)$} \\
\hline TIS $($ mean \pm SD) & $5.10 \pm 0.90$ & $5.00 \pm 0.88$ & $5.16 \pm 0.91$ & $0.211^{*}$ \\
\hline Mild (TIS = 0-2) & 1 & / & I & \\
\hline Mild (TIS = 0-2) & $164(82.0)$ & $66(84.6)$ & $98(80.3)$ & $0.441^{\star \star}$ \\
\hline Severe (TIS $\geq 6$ ) & $36(18.0)$ & $12(15.4)$ & $24(19.7)$ & \\
\hline
\end{tabular}

${ }^{*}$ t-test; ${ }^{* \star} \chi^{2}$ test

$A D$ - atopic dermatitis; Atopic disease - asthma, allergic rhinitis, and/or allergic conjunctivitis; SD - Standard deviation; TIS - Three-Item Severity score.

Table 2: The Children's Dermatology Life Quality Index (CDLQI) according to gender

\begin{tabular}{|c|c|c|c|c|}
\hline CDLQI (mean \pm SD) & All $(n=200)$ & Boys $(n=78)$ & Girls $(n=122)$ & $P^{*}$ \\
\hline Total score & $17.11 \pm 5.89$ & $16.20 \pm 5.94$ & $17.70 \pm 5.80$ & 0.217 \\
\hline 1. Symptoms & $2.22 \pm 0.70$ & $2.18 \pm 0.72$ & $2.25 \pm 0.70$ & 0.516 \\
\hline 2. Feelings & $1.61 \pm 1.11$ & $1.54 \pm 1.09$ & $1.65 \pm 1.13$ & 0.492 \\
\hline 3. Friendship & $1.86 \pm 0.85$ & $1.90 \pm 0.81$ & $1.84 \pm 0.87$ & 0.620 \\
\hline 4. Clothes/shoes & $1.59 \pm 0.89$ & $1.67 \pm 0.92$ & $1.54 \pm 0.86$ & 0.329 \\
\hline 5. Leisure/hobbies & $1.86 \pm 0.80$ & $1.72 \pm 0.85$ & $1.95 \pm 0.76$ & 0.051 \\
\hline 6. Swimming/sports & $1.56 \pm 1.04$ & $1.36 \pm 1.13$ & $1.69 \pm 0.97$ & 0.035 \\
\hline 7. School/holidays & $2.27 \pm 0.65$ & $2.13 \pm 0.69$ & $2.36 \pm 0.60$ & 0.013 \\
\hline 8. Teasing/bullying & $1.68 \pm 0.80$ & $1.44 \pm 0.85$ & $1.84 \pm 0.73$ & 0.001 \\
\hline 9. Sleep & $1.20 \pm 0.85$ & $1.03 \pm 0.90$ & $1.31 \pm 0.80$ & 0.020 \\
\hline 10. Treatment & $1.28 \pm 0.72$ & $1.26 \pm 0.75$ & $1.29 \pm 0.71$ & 0.714 \\
\hline
\end{tabular}

*t-test $\quad$ Bold values stand for statistical significance.

Table 3: Distribution of the overall CDLQI scores of boys and girls with AD according to the CDLQI banding

\begin{tabular}{llccc}
\hline CDLQI score & $\begin{array}{l}\text { Total } \\
\mathrm{N}(\%)\end{array}$ & $\begin{array}{l}\text { Boys } \\
\mathrm{N}(\%)\end{array}$ & $\begin{array}{l}\text { Girls } \\
\mathrm{N}(\%)\end{array}$ & $p$ \\
\hline No effect $(0-1)$ & $/$ & $/$ & $/$ \\
\hline Small effect $(2-6)$ & $4(2.0)$ & $4(5.1)$ & $/$ \\
\hline Moderate effect $(7-12)$ & $44(22.2)$ & $22(28.2)$ & $22(18.3)$ & 0.009 \\
\hline Very large effect $(13-18)$ & $64(32.3)$ & $18(23.1)$ & $46(38.3)$ & $52(43.3)$ \\
\hline Extremely large effect $(19-30)$ & $86(43.4)$ & $34(43.6)$ & \\
\hline
\end{tabular}

bies (1.86 \pm 0.80). Swimming/sports activities, school/holidays, teasing/bullying and sleep disturbances were more affected in girls (Table 2). Statistically significant difference in distribution of the overall CDLQI scores of boys and girls with $\mathrm{AD}$ according to the CDLQI banding is presented in Table 3. The effect of $\mathrm{AD}$ was more likely to be moderate in boys and very large in girls $(\mathrm{p}=0.009)$. 
Table 4: Correlation between CDLQI scores with AD severity (TIS score)

\begin{tabular}{|c|c|c|c|c|}
\hline CDLQI score & $\begin{array}{l}\text { Boys } \\
\text { Coefficient * }\end{array}$ & $p$ & $\begin{array}{l}\text { Girls } \\
\text { Coefficient * }\end{array}$ & $p$ \\
\hline Overall CDLQI & 0.39 & $<0.001$ & 0.62 & $<0.001$ \\
\hline Symptoms and feelings (questions 1 and 2) & 0.37 & 0.001 & 0.53 & $<0.001$ \\
\hline Leisure (questions 4,5 and 6 ) & 0.27 & 0.018 & 0.49 & $<0.001$ \\
\hline School/holidays (question 7) & 0.08 & 0.458 & 0.37 & $<0.001$ \\
\hline Personal Relationships (questions 3 and 8) & 0.46 & $<0.001$ & 0.47 & $<0.001$ \\
\hline Sleep (question 9) & 0.20 & 0.084 & 0.49 & $<0.001$ \\
\hline Treatment (question 10) & 0.35 & 0.001 & 0.53 & $<0.001$ \\
\hline
\end{tabular}

CDLQI - Children's Dermatology Life Quality Index

*Pearson's correlation coefficient. TIS - Three-item severity score; AD -Atopic dermatitis.

Bold values stand for statistical significance.

Overall CDLQI score and CDLQI subscale scores (except school/holidays and sleep in boys) significantly correlated with TIS (Table 4). In comparison with boys, stronger correlation was seen in girls for overall CDLQI score $(r=0.62$ for girls and $\mathrm{r}=0.39$ for boys) and CDLQI subscale scores. However, CDLQI overall score did not correlated significantly with the age of boys and girls $(\mathrm{r}=-0.09, \mathrm{p}=0.411$ for boys and $\mathrm{r}=$ $-0.10, p=0.271$ for girls $)$.

\section{DISCUSSION}

In this study the difference in overall CDLQI score between boys and girls was not significant $(P=0.217)$ that is in agreement with the results of previous studies. ${ }^{15,16}$ The international multi-centre study on self-assessed QoL in 167 $\mathrm{AD}$ non-matched children, 5-16 years old, from Ukraine, Czech Republic, Singapore, and Italy did not find any significant gender differences between boys and girls in CDLQI results..$^{15}$ In the matched analysis of the same international study in which each child in the group of boys (N $=36$ ) was matched to a corresponding child in the group of girls $(\mathrm{N}=36)$ from the same country whose age and SCORAD value were almost identical, Chernyshov et al. did not find differences in overall CDLQI. ${ }^{16}$ On the contrary, Kiebert et al. found a significant gender difference in QoL of older children with $\mathrm{AD}$ with significantly higher CDLQI scores in girls. ${ }^{10}$

In the present study girls with $\mathrm{AD}$ in comparison with boys, assessed CDLQI on swimming/ sports, school/holidays, teasing/bullying and sleep significantly higher. However, we did not find statistically significant differences between
According to multivariate logistic regression analyses statistically significant differences between two genders were not found for age, $\mathrm{AD}$ severity measured by TIS, concomitant atopic disease, and family history of atopic disease (data not shown).

The good internal consistency of the CDLQI was demonstrated with a Cronbach's alpha coefficient of 0.88 .

the two genders in the CDLQI subscale symptoms and feeling that is in contrast with the study conducted by Balci et al. ${ }^{23}$ In the matched study by Chernyshov et al. the CDLQI subscale on symptoms and feeling was assessed significantly higher by girls with AD. A gender difference was found for the item feelings while there was no gender difference in the assessment of the item symptoms. Girls were more embarrassed, self-conscious, upset and sad because of AD. ${ }^{16}$ Like Chernyshov et al. we did not find gender differences in problems with issues of clothes and shoes (changing and wearing different and special clothes or shoes because of child's skin). ${ }^{16}$ In contrast, Hon et al. reported that girls had more problems with clothes and shoes than did boys. ${ }^{12}$

In our study overall CDLQI score correlated well with disease severity that is in accordance with previous studies. ${ }^{9}, 15,16,24-26$ Besides the overall CDLQI score, the CDLQI subscale scores on symptoms and feelings, leisure, personal relationships, and treatment correlated well with disease severity in both genders, while signifi- 
cant correlation on school/holidays and sleep was found only in girls. In comparison with boys, stronger correlation was seen in girls for overall CDLQI score $(r=0.62$ vs. $r=0.39)$ and all CDLQI subscale scores. In the matched study conducted by Chernyshov et al. ${ }^{16}$ two separate items in boys (symptoms and feelings) and five items in girls (symptoms, feelings, friendship, playing and doing hobbies, and swimming) significantly correlated with $\mathrm{AD}$ severity. In our study the CDLQI item on problems with swimming and other sports was the sixth highly scored item in girls. In the study by Ang et al. ${ }^{27}$ this item was the second highly scored item, and one of the lowest scored items in the study by Chernyshov et al. ${ }^{16}$

To the best of our knowledge this is one of a few studies on gender differences of QoL in children with $\mathrm{AD}$ in Western Balkan with relatively high number of patients. However, some limitations of the present study should be mentioned. First, only children with moderate to severe forms of $\mathrm{AD}$ were enrolled in the study. The reason is that the most severe forms of $\mathrm{AD}$ are treated at the CCM, a tertiary health care center. Because of that it is not possible to generalize the results of our study to other patients affected by $\mathrm{AD}$ in the

\section{ACKNOWLEDGEMENTS}

This study was supported by the Ministry of Education, Science and Technological Development of the Republic of Serbia, Project No. 175025. We thank Professor Andrew Finlay, and Dr. Mohammad Basra, Department of Dermatology and Wound Healing, Cardiff University School of Medicine, Cardiff, UK, for the formal permission to translate and use the CDLQI in this study.

\section{REFERENCES}

1. Carroll CL, Balkrishnan R, Feldman SR, Fleischer AB Jr, Manuel JC. The burden of atopic dermatitis: impact on the patient, family, and society. Pediatr Dermatol 2005; 22:192-9.

2. Flohr C, Mann J. New insights into the epidemiology of childhood atopic dermatitis. Allergy 2014; 69:3-16.

3. Garg N, Silverberg JI. Epidemiology of childhood atopic dermatitis. Clin Dermatol 2015; 33:281-8. population of Montenegro. Second, like most authors, we did not apply matching in the analysis, although it has been recommended that gender differences can be adequately studied only if the children in the girls' and boys' groups were individually matched across groups for age and severity of AD. ${ }^{13}$

Although we did not find differences between the two genders in the overall health-related QoL, we confirmed the tendency for AD to have a more severe impact on girls' lives. For example, swimming/sports activities, school/holidays activities, teasing/bullying and sleep disturbance were more affected by girls. Symptoms, such as itching, scratching and pain and feeling such as embarrassment or self-conscious, upset or sad, were increased with $\mathrm{AD}$ disease severity in both genders, especially in girls who in general need more attention to their AD-related psychological problems. These results may influence treatment and counselling of children affected with AD. Doctors should focus on the prevention of avoidance behaviour in girls who have more severe $A D$, because such avoidance behaviour may affect other domains of girls' lives, like friendships, hobbies, sports, and even school work.

\section{CONFLICT OF INTEREST}

None.

4. Odhiambo JA, Williams HC, Clayton TO, Robertson $\mathrm{CF}$, Asher MI. Global variations in prevalence of eczema symptoms in children from ISAAC Phase Three. J Allergy Clin Immunol 2009;124:1251-8.e23.

5. Deckers IA, McLean S, Linssen S, Mommers M, van Schayck CP, Sheikh A. Investigating international time trends in the incidence and prevalence of atopic eczema 1990-2010: a systematic review of epidemiological 
studies. PLoS ONE 2012; 7:e39803. doi: 10.1371/journal.pone.0039803

6. Lewis-Jones S. Quality of life and childhood atopic dermatitis: the misery of living with childhood eczema. Int J Clin Pract 2006; 60:984-92.

7. Ganemo A, Svensson A, Lindberg M, Wahlgren CF. Quality of life in Swedish children with eczema. Acta Derm Venereol 2007; 87:345-9.

8. Chernyshov PV, Jirakova A, Ho RC, et al. An international multicenter study on quality of life and family quality of life in children with atopic dermatitis. Indian J Dermatol Venereol Leprol 2013; 79:52-8.

9. Ražnatović Djurović M, Janković J, Tomić Spirić V, Janković S. Health-related Quality of Life in Children with Moderate to Severe Atopic Dermatitis. Acta Dermatovenerol Croat 2015; 23:178-84.

10. Kiebert G, Sorensen SV, Revicki D, et al. Atopic dermatitis is associated with a decrement in health-related quality of life. Int J Dermatol 2002; 41:151-8.

11. Park CK, Park CW, Lee CH. Quality of life and the family impact of atopic dermatitis in children. Korean $\mathrm{J}$ Dermatol 2007;45:429-38.

12. Hon KL, Leung TF, Wong KY, Chow CM, Chuh A, Ng PC. Does age or gender influence quality of life in children with atopic dermatitis? Clin Exp Dermatol 2008; 33:705-9.

13. Chernyshov PV. Gender differences in health-related and family quality of life in young children with atopic dermatitis. Int J Dermatol 2012; 51:290-4.

14. Alzolibani A. Impact of atopic dermatitis on the quality of life of Saudi children. Saudi Med J 2014; 35:391-6.

15. Chernyshov PV, Ho RC, Monti F, et al. An international multicenter study on self-assessed and family quality of life in children with atopic dermatitis. Acta Dermatovenerol Croat 2015; 23:247-53.

16. Chernyshov PV, Ho RC, Monti F, et al. Gender Differences in Self-assessed Health-related Quality of Life in Children with Atopic Dermatitis. J Clin Aesthet Dermatol 2016; 9:19-24.

17. Hanifin JM, Rajka G. Diagnostic features of atopic dermatitis. Acta Derm Venereol (Stockh) 1980; 92:44-7.
18. Wolkerstorfer A, de Waard-van der Spek FB, Glazenburg EJ, Mulder PG, Oranje AP. Scoring the severity of atopic dermatitis: three item severity (TIS) score as a rough system for daily practice and as a prescreening tool for studies. Acta Derm Venereol 1999; 79:356-9.

19. Oranje AP, Glazenburg EJ, Wolkerstorfer A, de Waardvan der Spek FB. Practical issues on interpretation of scoring atopic dermatitis: the SCORAD index, objective SCORAD and the three-item severity score. Br J Dermatol 2007; 157:645-8.

20. Lewis-Jones MS, Finlay Y. The Children's Dermatology Life Quality Index (CDLQI): initial validation and practical use. Br J Dermatol 1995; 132:942-9.

21. Janković S, Vukićević J, Djordjević S, Janković J, Marinković J, Erić M. The Children's Dermatology Life Quality Index (CDLQI): linguistic and cultural validation in Serbian. J Cutan Med Surg 2013; 17:316-20.

22. Waters A, Sandhu D, Beattie P, Ezughah F, Lewis-Jones S. Severity stratification of Children's Dermatology Life Quality Index (CDLQI) scores. Br J Dermatol 2010; 163 (Suppl 1):121.

23. Balci DD, Sangün Ö, Inandi T. Cross validation of the Turkish version of Children's Dermatology Life Quality Index. J Turk Acad Dermatol 2007; 1:71402a. Available at: http://www.jtad.org/2007/4/jtad71402a.pdf

24. Ben-Gashir MA, Seed PT, Hay RJ. Quality of life and disease severity are correlated in children with atopic dermatitis. Br J Dermatol 2004; 150:284-90.

25. Monti F, Agostini F, Gobbi F, Neri E, Schianchi S, Arcangeli F. Quality of life measures in Italian children with atopic dermatitis and their families. Ital $J$ Pediatr 2011; 37:59.

26. Kim DH, Li K, Seo SJ, et al. Quality of life and disease severity are correlated in patients with atopic dermatitis. J Korean Med Sci 2012; 27:1327-32.

27. Ang SB, Teng CWC, Monika TP, Wee H. Impact of atopic dermatitis on health-related quality of life among infants and children in Singapore: a pilot cross-sectional study. Proceedings of Singapore Healthcare. 2014; 23:100-7. 